\title{
The Protective Effect of a Tariff Under Uncertainty
}

\section{Citation}

Helpman, Elhanan, and Assaf Razin. 1978. The protective effect of a tariff under uncertainty. Journal of Political Economy 86(6): 1131-1141.

\section{Published Version}

doi:10.1086/260731

\section{Permanent link}

http://nrs.harvard.edu/urn-3:HUL.InstRepos:3445093

\section{Terms of Use}

This article was downloaded from Harvard University's DASH repository, and is made available under the terms and conditions applicable to Other Posted Material, as set forth at http:// nrs.harvard.edu/urn-3:HUL.InstRepos:dash.current.terms-of-use\#LAA

\section{Share Your Story}

The Harvard community has made this article openly available.

Please share how this access benefits you. Submit a story.

Accessibility 


\section{CHICAgO JOURNALS}

The Protective Effect of a Tariff under Uncertainty

Author(s): Elhanan Helpman and Assaf Razin

Source: The Journal of Political Economy, Vol. 86, No. 6 (Dec., 1978), pp. 1131-1141

Published by: The University of Chicago Press

Stable URL: http://www.jstor.org/stable/1840400

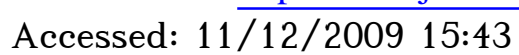

Your use of the JSTOR archive indicates your acceptance of JSTOR's Terms and Conditions of Use, available at http://www.jstor.org/page/info/about/policies/terms.jsp. JSTOR's Terms and Conditions of Use provides, in part, that unless you have obtained prior permission, you may not download an entire issue of a journal or multiple copies of articles, and you may use content in the JSTOR archive only for your personal, non-commercial use.

Please contact the publisher regarding any further use of this work. Publisher contact information may be obtained at http://www.jstor.org/action/showPublisher?publisherCode=ucpress.

Each copy of any part of a JSTOR transmission must contain the same copyright notice that appears on the screen or printed page of such transmission.

JSTOR is a not-for-profit service that helps scholars, researchers, and students discover, use, and build upon a wide range of content in a trusted digital archive. We use information technology and tools to increase productivity and facilitate new forms of scholarship. For more information about JSTOR, please contact support@jstor.org.

The University of Chicago Press is collaborating with JSTOR to digitize, preserve and extend access to The Journal of Political Economy. 


\title{
The Protective Effect of a Tariff under Uncertainty
}

\section{Elhanan Helpman}

Tel-Aviv University and University of Rochester

\section{Assaf Razin}

Tel-Aviv University

\begin{abstract}
We examine the protective effect of a tariff in a small economy with uncertainty and a stock market in which shares of firms are traded. In a deterministic economy, the allocation of resources is governed by commodity prices; in our economy, it is governed by equity prices and is dependent on commodity prices only to the extent that they influence equity prices. We show that in the absence of international trade in securities a tariff need not protect the import competing sector. In the presence of international trade in securities, a tariff always protects the import competing sector.
\end{abstract}

It is well known that in the standard deterministic two-sector economy the imposition of a tariff induces a resource flow from the export industry to the import competing industry if the external terms of trade do not change. This is the small-country case. It is also known that in the large-country case, that is, in the case in which a country's import (export) volume influences its external terms of trade, an imposition of a tariff may induce a resource flow out of the import competing industry and into the export industry. This is known as the Metzler Paradox (see Metzler 1949). In the smallcountry case, the imposition of the tariff necessarily reduces the internal terms of trade because the external terms of trade do not change. Since domestic competitive-resource allocation is governed by the internal terms of trade, the deterioration in the internal terms of trade which follows the tariff leads to an expansion of the import competing industry and to a contraction of the export industry. Hence, the tariff is protective in this case. In the large-country case, the imposition of a tariff may increase the external terms of trade at a rate which exceeds the rate of tariff, in which

Partial support from the Ford Foundation is gratefully acknowledged. 
case the internal terms of trade will improve, thereby reversing the direction of resource flow. If this happens, the tariff is said to protect the export industry and not the import competing industry.

It is the purpose of this paper to show that in the presence of uncertainty a tariff need not provide protection to the import competing industry even in the small-country case. The situation in which this may occur is one in which there is international trade in commodities but no international trade in securities. If there is international trade in securities, a tariff does provide conventional protection.

Our analysis relies on the model developed in Helpman and Razin $(1978 a, 1978 b)$. In this model there is a stock market in which shares of firms are traded. The allocation of the factors of production is governed by equity prices and depends on commodity prices only to the extent that they influence equity prices. In the absence of international trade in securities, domestic equity prices are internally determined, since domestic risks are then fully borne by domestic residents. Now, the imposition of a tariff in a small country worsens necessarily the internal commodity terms of trade in every state of nature. However, its impact on relative equity prices, which determines the interindustry resource flow, depends on whether the tariff will shift the demand for equities toward the import competing sector or away from it. If tariff proceeds are not redistributed back to consumers, then the shift in the demand for equities is ambiguous. We provide an example in which demand shifts toward the equities of the exportable industry; in this case, the tariff does not protect the import competing industry. We also show that when tariff proceeds are redistributed back to consumers in the form of lump-sum transfers, a "small" tariff protects the import competing industry if both goods are normal in consumption. (The difference between the two cases-with and without tariff proceeds redistribution-is explained at the end of the example.) This contrasts with the deterministic small-country case in which the redistribution policy is not important for the protective effect of a tariff (it is important though for the large-country case).

\section{The Model}

Our small economy consists of firms and consumers who operate in an uncertain environment generated by random production technology or random world prices. These random elements produce an incentive to develop financial capital markets, whose existence-in the form of stock markets - we assume. Domestic financial capital markets may or may not be integrated into the world's capital markets. If domestic capital markets are not integrated into the world's capital markets (i.e., there exists no international trade in securities), they enable risk sharing only among domestic residents. However, if domestic capital markets are integrated into the world's capital markets (i.e., there exists international trade in securities), 
they permit international risk sharing. Since we deal with international trade, we assume that there is international trade in commodities.

Input decisions have to be made before the resolution of uncertainty. As a result, firms face random profits and cannot undertake profit maximization. Instead, we assume - following Diamond (1967) - that firms choose their input levels so as to maximize their net value on the stock market; this procedure is equivalent to profit maximization whenever the relevant random elements become degenerate (i.e., their value becomes known with certainty). After the resolution of uncertainty, returns are realized and distributed to the firm's final stockholders.

Individuals play a double role in this economy. In the first stage-before the resolution of uncertainty-individuals choose a portfolio by means of trading in the stock market. An equity in a firm entitles the stockholder to a share in the firm's random return. This share equals the inverse of the number of the firm's outstanding equities. This is the stage in which individuals play the role of investors.

In the second stage-after the resolution of uncertainty-individuals use the proceeds from portfolios to purchase commodities. This is the stage in which they play the role of consumers.

Clearly, the two roles are interrelated. The ultimate goal of a portfolio chosen in the first stage is to provide consumption in the second stage. Hence, portfolio choice depends on preferences over consumption goods, but it also depends on probability beliefs, price expectations, and attitudes toward risk.

\section{Firms}

Consider a two-sector economy which produced two commodities, $X_{1}$ and $X_{2}$, by means of labor and capital. Each sector is composed of identical firms, and the output of each firm depends on its employment of capital and labor and on the state of nature that realizes. In particular, in every state $\alpha$, where $\alpha=1,2, \ldots, S$, the output of firm $j$ is

$$
Q_{j}(\alpha)=\theta_{j}(\alpha) f_{j}\left(L_{j}, K_{j}\right), \quad \alpha=1,2, \ldots, S
$$

where $\theta_{j}=$ a positive-valued random variable, $f_{j}(\cdot)=$ a standard neoclassical linear homogeneous production function, $L_{j}=$ labor input in firm $j, K_{j}=$ capital input in firm $j$, and $Q_{j}=$ output of firm $j$, which is also random. Since all firms in a given sector are identical and $f_{j}(\cdot)$ is linear homogeneous, equation (1) also describes the output of the sector to which firm $j$ belongs if $L_{j}$ and $K_{j}$ are interpreted as total factor inputs in this sector. We use this aggregation procedure and from now on use sectors as the production units. The index $j$ is used to denote sectors: $j=1,2$.

Assuming the existence of a stock market, it is explained in Helpman and Razin $(1978 a, 1978 b)$ that by selling shares in the stock market a firm in sector $j$ can be viewed as selling real equities of type $j$, where one real 


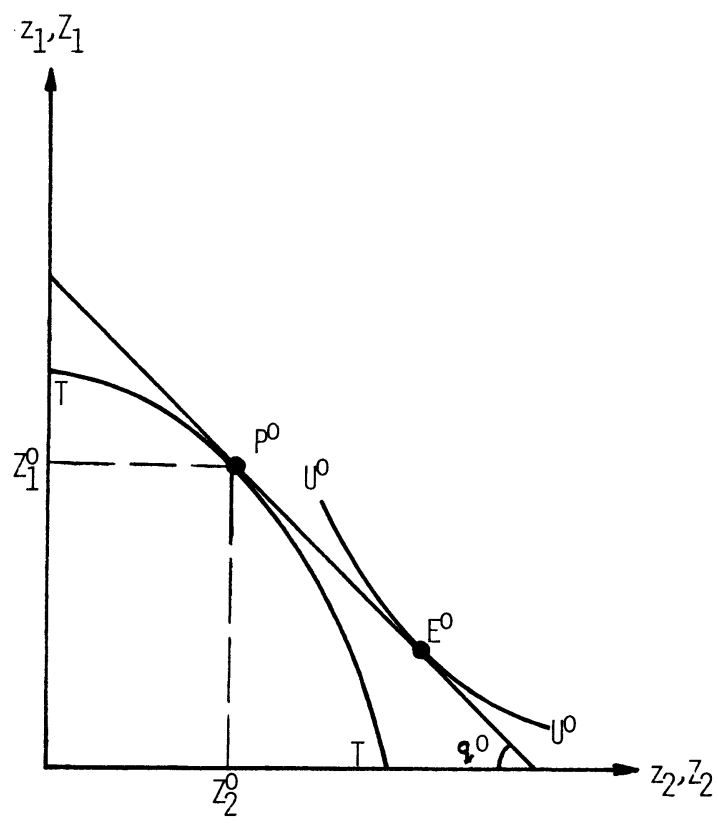

FIG. 1

equity of type $j$ provides the bundle $\left[\theta_{j}(1), \theta_{j}(2), \ldots, \theta_{j}(S)\right]$ of commodity $X_{j}$. The output of real equities of type $j$ by industry $j$ is $Z_{j}=f_{j}\left(L_{j}, K_{j}\right)$, and we can draw a transformation curve between real equities - $T T$ in figure 1. The curve TT has all the usual characteristics of a HeckscherOhlin type transformation curve.

It was shown in Helpman and Razin $(1978 a, 1978 b)$ that, given the relative price of type 2 real equities $q^{o}$ ( $q^{o}$ is the price of type 2 real equities divided by the price of type 1 real equities), net-value-maximizing firms choose in an equilibrium a point on the transformation curve $T \mathcal{T}$ at which the MRT (marginal rate of transformation) between $Z_{2}$ and $Z_{1}$ is equal to $q^{o}$. Hence, given $q^{o}$, production of real equities takes place at point $P^{o}$ in figure 1. Corresponding to point $P^{o}$, there is an equilibrium wage rate and rental rate on capital and an equilibrium allocation of the fixed supplies of labor and capital between the sectors. Given $P^{o}$, the output of commodities is not uniquely determined; it depends on the state of nature. If state $\alpha$ realizes, the output of commodity $i$ will be $\theta_{i}(\alpha) Z_{i}^{o}, i=1,2$.

By varying $q$ along $T T$, we trace out the general equilibrium supply functions :

$$
Z_{j}=Z_{j}(q), \quad j=1,2 .
$$

Glearly, for $q$ which does not result in complete specialization, $Z_{2}(\cdot)$ is an increasing function of $q$ (i.e., $\left.Z_{2}^{\prime}[q]>0\right)$, and $Z_{1}(\cdot)$ is a decreasing function of $q$ (i.e., $\left.Z_{1}^{\prime}[q]<0\right)$. In addition,

$$
Z_{1}^{\prime}(q)+q Z_{2}^{\prime}(q) \equiv 0
$$




\section{Consumers}

Let $v(p, I)$ be the representative consumer's indirect utility function, where $p$ is the price of $X_{2}$ in terms of $X_{1}$ and $I$ is income in terms of $X_{1}$. All consumers are assumed to be identical. Then, it is shown in Helpman and Razin (1978b, eq. [7]) that the consumer's portfolio choice is in equilibrium:

$$
\begin{array}{r}
\max _{z_{1}, z_{2}>0} E v\left[p(\alpha), \theta_{1}(\alpha) z_{1}+p(\alpha) \theta_{2}(\alpha) z_{2}\right], \\
\text { subject to } z_{1}+q^{o} z_{2} \leq Z_{1}\left(q^{o}\right)+q Z_{2}\left(q^{o}\right),
\end{array}
$$

where $z_{i}$ is the purchase of type $i$ real equities and $E$ is the expectations operator based on subjective probability beliefs. Commodity prices, which may be state dependent, $p(\alpha)$, are assumed to be given to our small country. It is assumed in equation (4) that individuals know the price ratio $p(\alpha)$ in every state (i.e., their price expectations are correct) but that they do not know which state will realize.

Assuming risk aversion, we can draw a set of assets-indifference curves convex to the origin, where an assets-indifference curve is defined as all combinations of $\left(z_{1}, z_{2}\right)$ for which the expected utility is constant. Then, the solution to equation (4) can be represented by the tangency of an assets-indifference curve to an assets-budget line, like point $E^{o}$ in figure 1. The curve $U^{o} U^{o}$ represents here the highest affordable expected utility level. Observe that points $P^{o}$ and $E^{o}$ in figure 1 represent an equilibrium in which there is international trade in equities and in which the rest of the world produces a perfect substitute for domestic type 2 real equities, which are imported. If there is no international trade in equities, the equilibrium domestic relative price $q$ will be such as to make $z_{i}=Z_{i}(q), i=1$, 2. Such an equilibrium is represented in figure 2 by point $P$ at which an assetsindifference curve is tangent to the transformation curve. Notice, however, that we are still assuming international trade in commodities after the realization of a state of nature at the prevailing world prices $p(\alpha)$.

At this point, the reader should note that the assets-indifference curves depend on the distribution of relative commodity prices. A shift in the price distribution pivots the entire assets-indifference map.

\section{Protection under Uncertainty}

Consider an ad valorem tariff on the second commodity, assuming that the second commodity is imported in every state of nature. The effect of the tariff on the allocation of resources between the two sectors differs according to whether international trade in securities takes place. We begin with the case of no international trade in securities, in which domestic residents bear all domestic risks. 


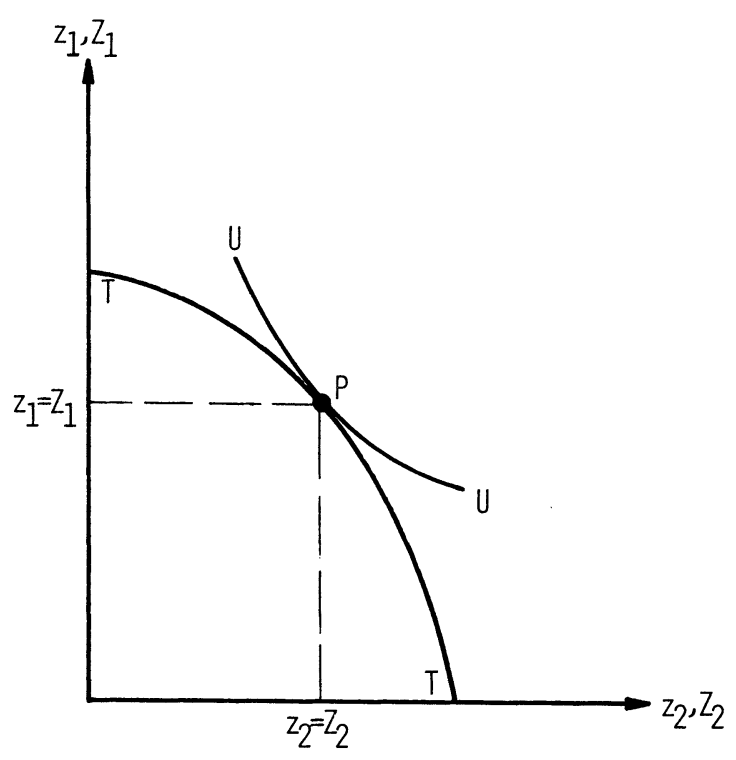

FIG. 2

\section{A. No International Trade in Securities}

The tariff-inclusive assets-indifference curves (which, along with the production possibilities curve, help determine the economy's production) are given by

$$
\begin{aligned}
E v\left[(1+t) p(\alpha) ; \theta_{1}(\alpha) z_{1}+(1\right. & +t) p(\alpha) \theta_{2}(\alpha) z_{2} \\
& +T(\alpha, t)]=\text { constant }
\end{aligned}
$$

where $t=$ the tariff rate (assumed to be state independent) and $T(\alpha, t)=$ state $\alpha$ expected lump-sum transfer payments. If tariff proceeds are redistributed back to consumers, $T(\alpha, t)$ is assumed to equal tariff proceeds in state $\alpha$. The consumer treats $T(\alpha, t)$ as a state-dependent lump-sum transfer; he does not relate it to the volume of imports, just like in the deterministic model. If tariff proceeds are not redistributed, $T(\alpha, t)$ equals zero in every state of nature. This is the relevant case if, for example, the government uses tariff proceeds in order to purchase commodities. (If the government's spending is related to the provision of public goods, our analysis is unaltered if we assume that the direct utility function is additively separable in private and public goods.) In the small-country deterministic case, a tariff protects the import competing industry independently of the way in which the tariff revenue is disposed of. In the present framework this is not so, which makes our distinction between the two extreme cases of the use of tariff revenue relevant. 


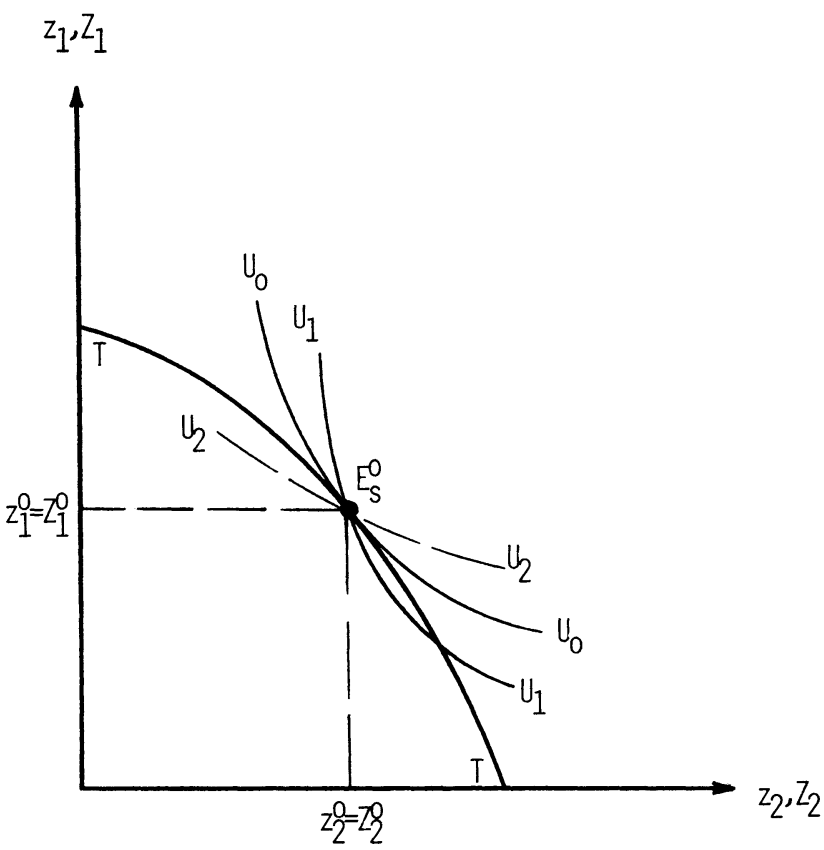

FIG. 3

The tariff-inclusive marginal rate of substitution (MRS) between real equity 2 and real equity $l$ is given by

$\operatorname{MRS}\left(z_{1}, z_{2} ; t\right) \equiv$
$\frac{E(1+t) p(\alpha) \theta_{2}(\alpha) v_{I}\left[(1+t) p(\alpha) ; \theta_{1}(\alpha) z_{1}+(1+t) p(\alpha) \theta_{2}(\alpha) z_{2}+T(\alpha, t)\right]}{E \theta_{1}(\alpha) v_{I}\left[(1+t) p(\alpha) ; \theta_{1}(\alpha) z_{1}+(1+t) p(\alpha) \theta_{2}(\alpha) z_{2}+T(\alpha, t)\right]}$.

Let us start with a discussion of the case in which tariff proceeds are not distributed back to consumers. In this case, individuals choose a portfolio expecting (correctly) no transfers after the realization of a state of nature.

$$
T(\alpha, t)=0 \text { for all } t \text { and } \alpha=1,2, \ldots, S \text {. }
$$

From equations (6) and (7) it is readily verified that a change in the tariff rate twists the assets-indifference curves at every point $\left(z_{1}, z_{2}\right)$ and changes the MRS between real equities 2 and 1 . This is because the tariff changes the mean as well as higher moments (such as the variance) of the distribution of the relative internal price of good 2.

In figure 3 , point $E_{s}^{o}$ denotes the pretariff stock market equilibrium in which the pretariff assets-indifference curve $U_{o} U_{o}$ is tangent to the production possibilities curve $T \mathcal{T}$. If the posttariff assets-indifference curve, which passes through the initial point $E_{s}^{o}$, is steeper than $U_{o} U_{o}$, as $U_{1} U_{1}$, the new equilibrium must be at a point on $T T$ to the right of $E_{s}^{o}$; that is, resources 
will move away from sector 1 and into the import competing sector, sector 2 - the standard case. If the posttariff assets-indifference curve which passes through $E_{s}^{o}$ is flatter than $U_{o} U_{o}$, as $U_{2} U_{2}$, the new equilibrium will be at a point on $T T$ to the left of $E_{s}^{o}$; that is, resources will move away from the importable goods sector and into the exportable goods sector. In the second case, a tariff does not protect the import competing sector, contrary to the deterministic case.

In order to see the factors which influence the "twist" in the assetsindifference curves, we derive the expression for the derivative of the assets' marginal rate of substitution evaluated at a zero tariff rate. Differentiating the right-hand side of equation (6), using equation (7), and evaluating the result at $t=0$, we obtain

$$
\begin{aligned}
& \frac{\partial \operatorname{MRS}\left(z_{1}, z_{2} ; 0\right)}{\partial t}=\mathrm{MRS} \\
& +\frac{E v_{I}(\boldsymbol{\alpha}) p(\alpha)\left\{-c_{2 I}(\boldsymbol{\alpha})+\left[c_{2}(\boldsymbol{\alpha})-\theta_{2}(\boldsymbol{\alpha}) z_{2}\right]\left[-v_{I I}(\boldsymbol{\alpha}) / v_{I}(\boldsymbol{\alpha})\right]\right\}}{\left[p(\boldsymbol{\alpha}) \theta_{2}(\boldsymbol{\alpha})-\operatorname{MRS} \theta_{1}(\boldsymbol{\alpha})\right]} \\
& +\frac{E v_{I}(\boldsymbol{\alpha}) \theta_{1}(\boldsymbol{\alpha})}{+}
\end{aligned}
$$

where $c_{2}$ is consumption of the second good, $c_{2 I}$ is the derivative of $c_{2}$ with respect to income, and $v_{I I}$ is the derivative of $v_{I}$ with respect to income. Variables which are state dependent are followed by an $\alpha$ in brackets. Thus, $c_{2}(\alpha)$ is consumption of good 2 in state $\alpha$. We have omitted in equation (8) functional representations of variables in order to gain clarity.

The first term on the right-hand side of equation (8) represents the direct effect of a tariff on the assets MRS. This effect is positive, implying that the direct effect is always protective. The second term summarizes the indirect effects which stem from changes in the marginal utility of income in every state of nature. The tariff affects the marginal utility of income via two routes: a direct income effect which arises from an increase in the return on type 2 real equities and a conventional price effect. The indirect effects are quite complicated, and they depend on marginal propensities to spend, import volumes, attitudes toward risk, etc. (Observe that $-v_{I I}[\alpha] / v_{I}[\alpha]$ is the absolute measure of risk aversion, and $c_{2}[\alpha]-\theta_{2}[\alpha] z_{2}$ equals imports if we evaluate eq. [8] at the initial equilibrium point at which $z_{2}=Z_{2}$.) The question that arises is whether the net indirect effect can be negative and sufficiently large in absolute value so as to outweigh the positive direct effect. The answer to this question is in the affirmative, as shown by the following example.

\section{Example}

Let the utility function be $u=\log \left(c_{2}+\log c_{1}\right)$. This yields the indirect utility function $v=\log \{[I /(1+t) p]-1+\log [(1+t) p]\}$, where $I$ stands for the consumer's disposable income in terms of good 1 . This implies 
(using eqq. [6] and [7]) that $\operatorname{MRS}\left(z_{1}, z_{2} ; t\right) \equiv\left\{E\left[\theta_{1}(\alpha)(1+t)^{-1} p(\alpha)^{-1}\right.\right.$ $\left.\left.z_{1}+\theta_{2}(\alpha) z_{2}-1+\log (1+t) p(\alpha)\right]^{-1} \theta_{2}(\alpha)\right\} \mid E\left[\theta_{1}(\alpha)(1+t)^{-1} p(\alpha)^{-1} z_{1}\right.$ $\left.+\theta_{2}(\alpha) z_{2}-1+\log (1+t) p(\alpha)\right]^{-1} \theta_{1}(\alpha)(1+t)^{-1} p(\alpha)^{-1}$. Assume now that $\theta_{2}(\alpha)=1$ for all $\alpha, p(\alpha)=1$ for all $\alpha, \theta_{1}(\alpha)>1$ for all $\alpha$, and that at the initial equilibrium $t^{o}=0$ and $z_{1}^{o}=z_{2}^{o}=1$. Since for $t^{o}=0$ we have $c_{1}^{o}=p(\alpha)=1$, the assumption $\theta_{1}(\alpha)>1$ assures that good 1 is initially exported and good 2 imported in all states. The stockholders' choice of these real equity holdings can be assured by an appropriate choice of production technologies and factor endowments. Then, the derivative of MRS with respect to $t$, evaluated at the initial equilibrium, is (see eq. [8]) $\partial \mathrm{MRS}$ $\left(z_{1}^{0}, z_{2}^{o} ; t^{o}\right) / \partial t=E\left[1 / \theta_{1}(\alpha)\right]-\left\{E\left[1 / \theta_{1}(\boldsymbol{\alpha})\right]^{2}-\left[E 1 / \theta_{1}(\boldsymbol{\alpha})\right]^{2}\right\}=E\left[1 / \theta_{1}(\boldsymbol{\alpha})\right]$ $-\operatorname{var}\left[1 / \theta_{1}(\alpha)\right]$, where var stands for variance. Thus, $E\left[1 / \theta_{1}(\alpha)\right]=$ MRS is the direct effect, while $-\operatorname{var}\left[1 / \theta_{1}(\alpha)\right]$ is the net indirect effect. Clearly, the net indirect effect is negative, and it dominates the direct effect for sufficiently large variances of $1 / \theta_{1}(\alpha)$. Hence, for var $\left[1 / \theta_{1}(\alpha)\right]$, sufficiently large $\partial \operatorname{MRS}\left(z_{1}^{o}, z_{2}^{o} ; t^{o}\right) / \partial t<0$, implying that, for a "small" tariff, $U_{2} U_{2}$ in figure 3 is the posttariff assets-indifference curve. Therefore, in this case, the imposition of the tariff leads to a contraction of the import competing industry and an expansion of the export industry.

In the absence of uncertainty, the variance of $1 / \theta_{1}(\alpha)$ is zero, and the paradoxical result does not arise. In the presence of uncertainty, the paradoxical result can arise because of the negative effect that an increase in $t$ has on the demand for type 2 real equities, holding their returns constant. This can be seen as follows. Write the indirect utility function as $v=\log$ $\left\{\theta_{1}(\alpha)(1+t)^{-1} z_{1}+z_{2}-1+B(t)\right\}$, where $B(t)=\log (1+t)$. It can be shown that an increase in $B$ reduces the demand for type 2 real equities. Now, an increase in the tariff rate has two effects. It increases $B$, resulting in a decline in the demand for type 2 real equities, and increases the return on type 2 real equities, resulting in an increase in their demand. The first effect dominates when $\operatorname{var}\left[1 / \theta_{1}(\alpha)\right]$ is sufficiently large.

Consider now the case in which tariff proceeds are redistributed back to consumers. In this case, state $\alpha$ transfers (i.e., the tariff rate $\times$ the value of imports) are implicitly given by

$$
\begin{gathered}
T(\alpha, t) \equiv \operatorname{tp}(\boldsymbol{\alpha})\left\{c _ { 2 } \left[(1+t) p(\alpha) ; \theta_{1}(\alpha) z_{1}+(1+t) \theta_{2}(\alpha) p(\alpha) z_{2}\right.\right. \\
\left.+T(\alpha, t)]-\theta_{2}(\alpha) z_{2}[q(t)]\right\},
\end{gathered}
$$

where $c_{2}(\cdot)=$ the second commodity demand function, $\theta_{2}(\alpha) Z_{2}(\cdot)=$ the local output of good 2 in state $\alpha$, and $q(t)$ is the equilibrium relative price of real equity 2 which is a function of the tariff rate. Notice that from equation (9), we get

$$
\begin{aligned}
& T(\alpha, 0)=0 \\
& \frac{\partial T(\alpha, 0)}{\partial t}=p(\alpha)\left\{c_{2}\left[p(\alpha) ; \theta_{1}(\alpha) z_{1}+\theta_{2}(\alpha) p(\alpha) z_{2}\right]-\theta_{2}(\alpha) Z_{2}(q)\right\}
\end{aligned}
$$




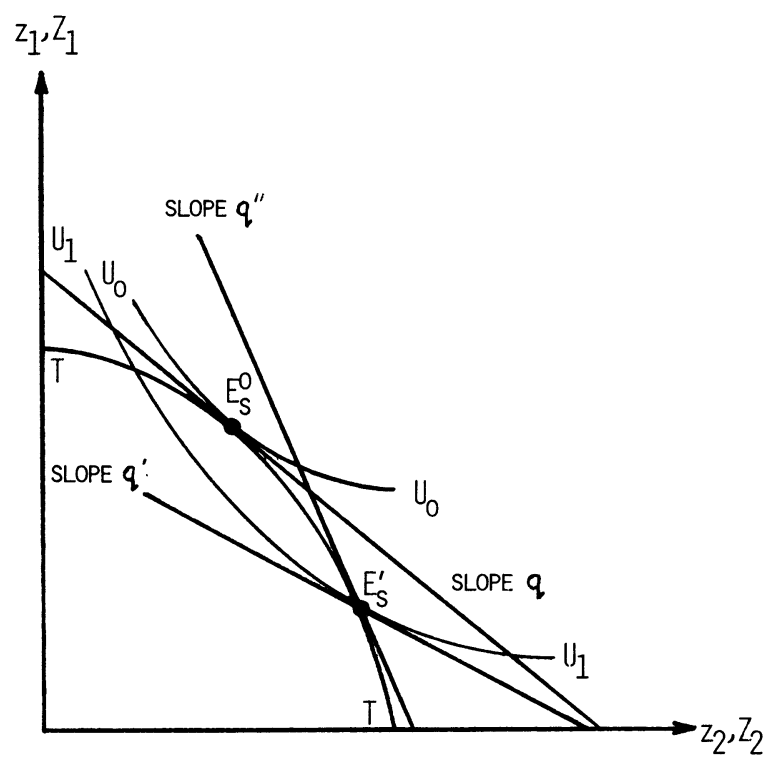

FIG. 4

That is, a zero tariff rate gives rise to a zero amount of tariff proceeds, and the rate of change in the tariff proceeds for a small tariff is equal to imports evaluated at world prices. Individuals choose a portfolio expecting to receive a lump-sum transfer of $\mathcal{T}(\alpha, t)$ in state $\alpha, \alpha=1,2, \ldots, S$ (they are not aware of the relationship given in eq. [9]).

Now we show that if both goods are normal the paradoxical result cannot appear in the case of a small tariff. In order to see this, differentiate equation (6) with respect to $t$ and evaluate it at $t=0$, using equation (10), to obtain $\partial \operatorname{MRS}\left(z_{1}, \quad z_{2} ; 0\right) / \partial t=\left[1 / E v_{1}(\alpha) \theta_{1}(\alpha)\right]\left\{E v_{I}(\alpha) p(\alpha) \theta_{2}(\alpha)+E v_{I p}(\alpha)\right.$ $[p(\alpha)]^{2} \theta_{2}(\alpha)+E v_{I I}(\alpha)[p(\alpha)]^{2} c_{2}(\alpha) \theta_{2}(\alpha)-\operatorname{MRS}\left(z_{1}, z_{2} ; 0\right)\left[E v_{I p}(\alpha) p(\alpha)\right.$ $\left.\left.\theta_{1}(\alpha)+E v_{I I}(\alpha) p(\alpha) c_{2}(\alpha) \theta_{1}(\alpha)\right]\right\}$, where $v_{I p}$ is the derivative of $v_{I}$ with respect to its first argument.

Since $v_{I p}=v_{p I}=\partial\left(-v_{I} c_{2}\right) / \partial I=-v_{I I} c_{2}-v_{I} c_{2 I}$ and $p c_{2 I}=1-c_{1 I}$, we can substitute these relationships in the above expression to obtain $\partial \operatorname{MRS}\left(z_{1}, z_{2} ; 0\right) / \partial t=\left[1 / E v_{I}(\alpha) \theta_{1}(\alpha)\right]\left[E v_{I}(\alpha) p(\alpha) \theta_{2}(\alpha) c_{1 I}(\alpha)+\operatorname{MRS}\left(z_{1}\right.\right.$, $z_{2}$; 0) $\left.E v_{I}(\alpha) \theta_{1}(\alpha) p(\alpha) c_{2 I}(\alpha)\right]$. If both goods are normal, the marginal propensities to spend on them are positive and the above expression is positive. This means that for normal goods a small tariff will twist the assets-indifference curves in figure 3 so as to make them steeper, like from $U_{o} U_{o}$ to $U_{1} U_{1}$ and thus provide protection to the importable goods sector.

Finally, observe that an equity subsidy-i.e., a subsidy given to an industry at the financing stage - - will unambiguously induce the expansion of that industry. In figure 4 we reconstruct the initial equilibrium shown in figure 3 , the real equity-price ratio being $q$. A subsidy to sales of real equity 2 decreases to $q^{\prime}$ the relative price of real equity 2 to investors and drives a 
wedge between that relative price and the marginal rate of transformation $q^{\prime \prime}$, leading to a new equilibrium $E_{s}^{\prime}$. In this case, resources will move away from sector 1 and into sector 2 .

\section{B. International Trade in Securities}

Now consider the case in which the economy trades with the outside world in both commodities and securities. By the small-country assumption, without a tariff, commodity prices and security prices are given to the home country. A tariff raises the local price of the importable goods, but how does a tariff affect the importable-good industry's stock market value? It is explained in Helpman and Razin (1978b) that a tariff at a rate of $100 t$ percent, which increases the price of the second commodity by $100 t$ percent in every state of nature, increases by $100 t$ percent the return on each unit of domestic type 2 real equities. This will result in a $100 t$ percent increase in the price of local type 2 real equities in order to eliminate profitable arbitrage. The local type 2 real equity provides a return of $(1+t) \theta_{2}(\alpha) p(\alpha)$ in state $\alpha$ while the foreign type 2 real equity provides a return of $\theta_{2}(\alpha) p(\alpha)$ in state $\alpha$. Hence, one unit of a local type 2 real equity is now equivalent to $(1+t)$ units of foreign type 2 real equities. This means that the price of local type 2 real equities increases from $q$ to $(1+t) q$. Thus, following a tariff, resources will move necessarily away from the exportable-good industry and into the importable-good industry, as in the deterministic case.

\section{References}

Diamond, Peter A. "The Role of a Stock Market in a General Equilibrium Model with Technological Uncertainty." A.E.R. 57 (September 1967) : 759-76.

Helpman, Elhanan, and Razin, Assaf. "Uncertainty and International Trade in the Presence of Stock Markets." Rev. Econ. Studies 45 (June 1978) : 239-50. (a)

$\rightarrow-$."Welfare Aspects of International Trade in Goods and Securities." $Q . \mathcal{F}$. E. 92 (August 1978) : 489-508. (b)

$\rightarrow$ Metzler, Lloyd A. "Tariffs, the Terms of Trade and the Distribution of National Income." 7.P.E. 57, no. 1 (February 1949): 1-29. 